\title{
PERSISTENT PERSUASION UPAYA EFEKTIF PENANAMAN NILAI MORAL
}

\author{
Amitya Kumara \\ Universitas Gadjah Mada
}

\begin{abstract}
Moral violation among students, from elementary school unfil high school, is increasing both in quantity and quality. The govemment has put in efforts to overcome this problem through moral and ethic lessons. On the other hand, parents encounter problems in upholding the rules for children. In the other words, parents have not found an effective way to plant moral lassons (Andiayani, 2000).

An effective form of communication results from the combination of father child and mother child interaction quality, using persuasive expressions persistently, avoiding physica! punishments, and expressions indicating self esteem (Elizabeth and Cardlyn, 1999; Maria, 1999).

A qualitative method was used in the case study. The research subjects consist of preschool students until first graders of 4 to 7 years old. Student's interaction, both with teachers $x$ school and with parents a home, was observed with structureless observation method, and followed by interviews with teachers and parents. The observation settings are as follows: 1) houses; 2) Sunday school; 3) Play group; 4) Taman Siswa Elementary School; 6) Kindergarten.

Findings: 1) Toleration, honesty, courage, and forgivingness are moral values which are more often conveyed by teachers to students at schaol, 2) moral values which are taught concerns more with the completion of school warks, 3) not many teachers covey warnings in Javanese language; 4) warnings conducted by parents consist of a more angry characteristic and not of advice; 5 moral values taught at home concerns more with obedience towards parents, disciplinary and diligence.
\end{abstract}

Key words : persistent persuasion

\section{Pengantar}

Penanaman nilai moral bukanlah hal yang mudah. Persoalan ini telah menjadi kepedulian pendidik hingga pemerintah, semisal pemerintah melalui Dirjen Pendldikan Dasar dan Menengah telah menganjurkan untuk mengajarkan mata pelajaran budi pekerti di sekolah-sekolah, mulai dari tingkat Sekolah Dasar hingga Sekolah Menengah Atas. Namun kenyataannya belum semua sekolah menanggapinya secara positif. Hanya beberapa sekolah yang memiliki orientasi keagamaan tertentu, sudah dengan menerapkan anjuran tersebut.

Para pendidik sebagian berpendapat adalah terlambat dan tidak semestinya guru bertanggung jawab mengajarkan pembelajaran budi pekerti. Para pendidik berpendapat, orang yang paling tepat dan akurat dalam pengajaran budi pekerti adalah orangtua, dan seyogyanya diajarkan sebelum anak masuk sekolah dasar, dan cara mengajarkannya pun secara persistent persuasion.

Hasil pengamatan dan konsultasi peneliti, menunjukkan adanya keluhan orang tua. Orangtua menanyakan apa yang harus mereka lakukan untuk menangani anak yang 
bermasalah. Studi eksplorasi yang dilakukan oleh Andayanl (2000) menunjukkan bahwa orangtua mempunyal masalah dalam menegakkan aturan disiplin, serta menanamkan nilai-nilai moral pada anak. Masalah InI dapat bersumber terutama pada ketidaktahuan orangtua tentang aturan apa yang seharusnya ditegakkan serta ketidaktegaan orangtua untuk menerapkan sangsi yang efeklif kepada anak. Apa yang dilakukan oleh orangtua hanya menyebabkan anak belajar bagaimana berkilah atau menghlndari efek tidak menyenangkan dari suatu kesenangan yang diperolehnya dari perilakunya.

Masalah yang dihadapi orangtua d atas, diduga disebabkan orangtua belum menemukan cara-cara yang efektif untuk menanamkan nilai moral. Cara-cara yang lazim mereka gunakan dalam rangka menegakkan nilai moral adalah menghukum anak, mulai darl yang rlngan seperti ungkapan-ungkapan verbal yang menyakitkan hati, hingga tidak jarang anak mendapatkan hukuman fisik yang tidak sepadan dengan pelanggaran yang dilakukan, yang tidak saja mengakibatkan luka fisik namun juga hati.

Manifestasi perilaku bermasalah ditunjukkan oleh perilaku agresi, berperilaku oposisi-melawan, menentang, menarik diri, ketidaktrampilan melakukan adaptasi, dan perubahan mood yang sangat sering terjadi, dan berlangsung tiba-tiba dan terkadang tidak terkendall (Fagot, 1995). Sedangkan yang dimaksud masalah perilaku opisisi adalah ketidakmampuan menyesuaikan diri, agresl, tidak patuh yang dialami anak selama kurang lebih enam bulan terakhir (Stormshakdan Webster-Stratton, 1999).

Seianjutnya penelitian yang diiakukan oleh Luria (1971) menyatakan bahwa penanaman moral yang mengandalkan pada raslo, hukuman, dan hanya disampaikan oleh ibu ternyata tidak efektif. Bentuk penyampalan nllai moral yang efektif merupakan hasii perpaduan antara kualitas Interaksi Bapak-Anak, dan lbu-Anak, serta menggunakan ungkapan persuasi secara persistent, menghindari hukuman fisik, dan ungkapan yang menyinggung harga diri
(Elizabeth dan Cardlyn, 1999; Maria, 1999).

\section{Dasar Teori}

Persistent Persuasion adalah keterlibatan orang dewasa secara terus menerus dalam memberi pengarahan sampai seorang anak mematuhi anjuran tersebut, namun tanpa disertal kekuatan fisik maupun ancaman kekerasan. Petunjuk disampaikan secara rasional dengan disertai kekuatan emosi yang sepadan dan disampaikan dengan nada suara tertentu. Tidak ada ancaman atau secara bertahap terjadi peningkatan nada suara yang bermusuhan. Tidak ada kalimat "tidak boleh tidak" baik secara Implisit maupun eksplisit yang menyertai kalimat anjuran. Orang dewasa dapat mengungkapkan kemball pernyataan atau memberikan tambahan keterangan yang rasional agar agar terjadi kepatuhan, dan masing-masing pengulangan yang dilakukan oleh orang dewasa dapat dipandang sebagai upaya anak untuk melakukan negosiasi, namun nada suara tetap terkendali, masuk akal dan bahkan bersahabat (Bergin dan Bergin, 1999).

Interaksi orangtua-anak tidak hanya meiibatkan aspek kepribadian, ketrampilan sosial, perkembangan moral, kehangatan, dan disiplin namun demikian juga aspek kognitif (Vuchnich \& Coughlin, 1992). Oranglua berperan sebagai fasflitator aktif bagi perkembangan kognitif anak. Oleh karena itu aspek mendasar dart pengasuhan adalah ketrampilan interpersonal-linguistic, seperti memberi nama, melakuken kategorisasi, mengarahkan, menjelaskan dan menguraikan peristiwa-peristiwa yang terjadi di sekitar kepada anak, maka melalul cara-cara penyampaian seperti inilah penanaman nilai morai akan efektif (Lakso, 1995).

Selanjutnya Imhoff dan Baker-Ward (1999) dan Saywltz (1995) menyarankan menggunakan bahasa yang memadai sesuai usia anak dan perkembangan kognitlf anak agar diperoleh respon yang optimal. Mereka menyarankan agar dlgunakan konstruksi kalimat tertentu yang blasa digunakan 
secara teratur dalam pembicaraan seharihari. Kalimat-kalimat yang periu dihindari adalah kalimat yang mengandung embedded clauses, tiga sampai empat kata, pronouns, dan menggunakan kalimat yang menunjukkan relasi seperti lebih banyak lebih sedikit, dan kalimat pasif.

Faktor yang mempengaruhi kualitas kepatuhan merupakan hasil interaksi ubahan sebagai berikut: ketrampilan guru (Bergin dan Bergin, 1999); teknik penyampaian (Bergin dan Bergin, 1999); kendali emosi (Bergin dan Bergin, 1999); kemampuan berbahasa anak (Luria, 1971); perbedaan strategi komunikasi antara Bapak dan ibu terhadapanak (Lakso, 1995).

Pada masa kanak-kanak, anak belajar beberapa ketrampilan penting dalam berhubungan dengan teman sebaya, misalnya bagaimana bermain dengan teman, menggunakan permainan bersama, dan bergiliran serta berbagi pengalaman. Sebagai tambahan ketrampilan belajar, berinteraksi dengan teman juga menfasilitasi perkembangan ketrampilan mengatasi konfllk, strategi negosiași (Gottman dan Metteal, 1987; Shantz dan Hobart, 1989). Kualitas relasi anak dengan teman sebayanya pada usia inl sangat penting dan dapat digunakan untuk meramal kesuksesan akademis dan pengalaman bersekolah (Ladd dan Price, 1987). Namun demikian, untuk beberapa anak kemampuan untuk membentuk posifive poer relations adalah tidak mudah untuk dicapaí. Analisis multifaktorial mengkajl tugas perkembangan dengan permasalahan yang dihadapi anak. Pada kasus tertentu anak yang mengalami masalah dengan teman sebaya dicirikan sebagai anak yang hiperaktif baik d rumah maupun di sekolah. Itulah sebabnya mengapa peran orangtua sangat penting agar anak mampu berinteraksi secara lancar dengan teman sebaya yang berpedoman pada nilai-nilai moral yang universal.

Pendidikan moral dapat disejajarkan dengan pendidikan karakter, artinya mengajarkan sebuah ketrampilan kepada anak agar dapat menetapkan sebuah perilaku itu baik atau buruk, melalui berbagai cara pendekatan, misalnya dongeng, berorganisasi, bersosialisasl, menlru model. Piaget (wwww uts eddu/stagesmoral html) mengemukakan dua tipe pembelajaran moral yaitu: a) morality of constraint atau heteronomy yang dicirikan sebagai penghargaan yang unilateral terhadap orangtua atau flgur authorities, bentukbentuk perilaku yang ditunjukkan adalah kepatuhan; b) morality of cooperation atau aufonomy yang berkembang setelah fase pertama dikuasal yang dicirkan dengan saling menghargai, Konformitas berdasarkan identifikasi tujuan bersama dan saling kepedulian.

Teori perkembangan moral dari Kohiberg (1981) mengidentifikasl tlga tahap perkembangan moral sebagai berikut:

Tabel 1. Tahap perkembangan moral Kohiberg

\begin{tabular}{|c|c|c|}
\hline Level & Stage & Behavlor \\
\hline 1. Preconventional & $\begin{array}{l}\text { 1. Punishment and obedionce } \\
\text { orientation } \\
2 \text { instrumental orientation }\end{array}$ & $\begin{array}{l}\text { Obeys rules to avoid } \\
\text { punishment } \\
\text { Obevs rules ti receive rewards }\end{array}$ \\
\hline II. Conventional & $\begin{array}{l}\text { 3. Good child orientation } \\
\text { 4. Law and order orientation }\end{array}$ & $\begin{array}{l}\text { Conforms to rules to avoid } \\
\text { disapproval by others } \\
\text { Conforms to rules to maintain } \\
\text { social order }\end{array}$ \\
\hline III. Postconventional & $\begin{array}{l}\text { 5. Morality of contract, } \\
\text { individual rights, and } \\
\text { democratically accepted law } \\
\text { 6. Morality of individual } \\
\text { principles and conscience }\end{array}$ & $\begin{array}{l}\text { Accepts and follows laws for } \\
\text { the weifare of the larger } \\
\text { community. } \\
\text { Believers in and follows self- } \\
\text { chosen univert al ethical } \\
\text { principles }\end{array}$ \\
\hline
\end{tabular}


Pada tahap pre-konvensional penilaian moral dicirikan dengan perspectif individual yang kongkret, fokus orientasi pada menghindari hukuman dengan menunjukkan kepatuhan, ditunjukkan hubungan vertlkal antara orangtua pengasuh dengan anak. Pada tahap konvensional sudah melibatkan hubungan timbal balik, artinya aturan yang ditujukan kepada anak haruslah menumbuhkan minat anak untuk mengikutinya,dengan memperhatikan dan mempertimbangkan nilai-nilai konvenslonal yang berfungsi di lingkungan tempat tinggalnya lingkungan sosialnya, ditandal dengan hubungan horisontal dengan teman sebayanya maupun dengan saudara-saudaranya. Pada tahap ke tiga post-konvensional, nilai-nilai moral diperluas dengan memperhatikan standar yang disepakatl secara universal, prinsip etika, serta menghargai martabat manusia.

Baik Plaget maupun Kohlberg membangun teori perkembangan moral sejalan dengan perkembangan kognitif, yang menegaskan perkembangan moral diartikulasi pada setiap tahapan dari ketidakmatangan mengarah ke perkembangan kematangan moral seiring dengan kematangan perkembangan kognitif, yang ditandai dengan perkembangan penalaran. Piaget maupun Kohlberg sependapat bahwa keluarga berperan penting dalam mengajarkan nilai moral, keluarga peletak dasar yang utama dan pertama untuk penanaman moral. Pengenalan dan pengalaman berinteraksi dengan lingkungan diawali dari lingkungan keluarga. Selanjutnya pengalaman diperiuas ketika anak semakin luas pergaulannya yang akan memperkuat konstruksi moral dan pengetahuan sosial dengan beragam perspektif.

\section{Pertanyaan Penelltian}

Dari uralan d atas, penelitian ini bertujuan untuk mendapat gambaran :

1) Perilaku oposisi seperti apa yang ditunjukkan siswa?

2) Nilai moral apa saja yang diajarkan di

\section{sekolah dan di rumah?}

3) Media apa dan bagaimana cara mengajarkan nilai moral tersebut?

4) Adakah ungkapan bahasa Jawa yang digunakan?

\section{Metode}

Penelitlan ini bertujuan memberikan gambaran penyampaian nilai moral d tujuh setting pembelajaran anak. Oleh karena itu metode observasi dan wawancara naturalistik adalah yang paling tepat ( Shiraev \& Levy, 2004). Adapun tujuh setting pembelajaran adalah sebagal berikut: 1) rumah, 2) Taman bermain; 3) Taman kanakkanak; 4) Taman Pendidikan Al Quran; 5) Sekolah Dasar Islam Terpadu; 6) Sekolah DasarTaman S|swa; 7) Sekolah Minggu.

Subjek penelitian adalah siswa yang menurut persepsi guru ataupun orang tua mengalami hambatan dalam berinteraksi dengan teman sebaya. Hal ini disebabkan siswa tersebut belum memiliki ketrampilan bergaul dengan kata lain ada hambatan mengaplikasikan nilai nilai moral dalam pergaulan. Bentuk bentuk hambatan antara lain suka melawan perintah guru, membuat keributan di kelas, tidak mau mengerjakan tugas. Di samping siswa, guru dan orangtua siswa yang bermasalah menjadi subjek penelitian ini. Pengamatan dilakukan sewaktu pelajaran berlangsung serta melakukan wawancara untuk mengetahui lebih lanjut perkembangan masalah siswa.

Prosedur melakukan observasi dan wawancara adalah sebagai berikut:

1) Pengamat menjelaskan maksud kedatangan, tujuan penelitian, menegaskan kesedlan untuk berpartisipasi dan menyampaikan inf ormed concent.

2) Pengamat melakukan pendekatan dengan cara menjadl baglan dari tempat pembelajaran sehingga subjek (slswa, anak, guru ataupun oranglua) merasa nyaman dengan keberadaan pengamat.

3) Pengamat mencatat perilaku-perilaku subjek penelitian secara verbatim. Pengamat perlu mencermati jenis-jenis perilaku dan komunikasi verbal maupun 
non-verbal yang mencerminkan penguasaan atau ketidakpahaman terhadap nilat moral pada anak, ada tidaknya sosialisasi moral oleh guru atau orangtua, dan cara sosialisasi.

4) Pengamat memilih konteks yang memungkinkan munculnya perilaku yang mencerminkan moralitas (misalnya waktu bermain, belajar, makan bersama, menerima kunjungan tamu).

5) Pengamatan dilakukan sampal informasi sudah diperoleh artinya tidak dibatasi waktu maupun frekuensi kunjungan, akan tetapi berdasarkan kecukupan informasi

6) Pengamatan dilakukan setelah mendapat Ijin baik oleh guru maupun orangtua, tempat pengamatan di kelas maupun di rumah untuk mengamati perilaku dan komunikasi guru-siswa dan orangtua anak.

Petunjuk melakukan pendekatan dengan guru sebelum pengamatan dilakukan:

1) Tanyakan apakah ada siswa yang mengalami masalah sebagai berikut: a) kemampuan akademik, berilah sekor $1-5$ jika nilainya semakin jauh dari rata-rata kelas; b) adaptasi artinya kendala fungsi penyesuaian diri di kelas, tertinggal dari teman-temannya, tidak punya teman dan sering melanggar disiplin; c) perilaku yang nampak misalnya suka mengganggu, usil, nakal, tidak bisa duduk diam, susah diatur; d) emosional misal temperamental, mudah marah. Lanjutkan dengan pertanyaan penjelas sebagal berikut berapa kali masalah siswa tersebut muncul ketika guru sedang mengajar dan bagaimana perasaan ataupun tindakan guru?

2) Topik moral apa yang diajarkan d! sekolah? Adakah perbedaan perlakuan dan harapan terhadap siswa laki-laki dan perempuan? Apakah diberikan penghargaan jika menunjukkan perilaku yang baik?

3) Adakah sangsi yang diterapkan kepada siswa jika yang bersangkutan melanggar moral? Bentuk sangsi yang diberikan, apakah langsung, penalaran moral, atau diadili.
Berikut adalah hal-hal penting yang perlu direkam sewaktu melakukan pengamatan baik di rumah, maupun di sekolah:

1. Adakah perilaku moral yang tidak sesuai dengan teori tahap perkembangan moral? Jelaskan bentuknya seperti apa?

2. Apakah siswa cepat beradaptasi dengan lingkungan? Apakah melibatkan aspek afektif ? Emosi spesifik apa yang muncul saat dilakukan pengamatan?

3. Adakah perilaku non verbal yang mengindikasikan keakraban maupun konflik?

4. Perhatikan bagaiman guru/orangtua mengaplikasikan nilai-nilal moral dalam proses pembelajaran sehari-hari.

5. Adakah perilaku guru yang kurang tepat untuk menegakkan disiplin? Misalnya waktu yang lama untuk menghukum, menghukum secara berulang-ulang anak yang melanggar disiplin.

Petunjuk wawancara dengan orang tua sebagal berikut:

1. Bagaimana orangtua menilai anak? Eksplorasi persepsi tentang perilaku anak terhadap saudara , teman, orang dewasa lain, rincian penggambaran sangat dipertukan, apakah suka membaca atau tidak?

2. Apakah orangtua terlibat dalam pengasuhan anak? Jika ya, siapa pengasuh utama? Apa alasannya? Jika tidak, mengapa? Eksplorasi masalah kesempatan, sikap, nilai tentang pengasuhan anak

3. Dalam pengasuhan nilai-nilai apakah yang disosialisasikan dan diajarkan? Slapa yang mengajarkan nilai moral dan bagaimana caranya?

Eksplorasi aspirasi atau cita-cita orangtua terhadap anak, apa yang boleh dan tidak boleh dilakukan, apa yang baik dan yang buruk? Apa alasannya? Adakah pengalaman pribadi berkaitan dengan nilai-nilai tersebut?

4. Nilai-nilai moralitas yang điajarkan (bisa sama atau berbeda dengan no 3 ). Eksplorasi apakah ada nilai-nilai yang diambil dari budaya Jawa, diminta memberikan contoh (kalau tahu 
peribahasanya diminta menyebutkan) jika ada apa alasannya? Jika tídak mengapa?

5. Bagaimana cara mengajarkan nilai-nilai moral? Eksplorasl perilaku misal keteiadanan, kalimat-kalimat yang digunakan untuk menekankan arti nilai (termasuk metafora yang digunakan), konteks saat mengajarkan nilal. Eksplorasi keterlibatan orangtua dalam mengajarkan nilai-nilal, bagaimana keterlibatan pasangan menurut persepsi masing-masing. Jika keterlibatan diperseps| sangat kurang bagaimana penjelasannya?

6. Bagaimana reaksi anak terhadap ajaran nilal? Apakah anak sudah mampu melakukan seleksi dan kontrol moral? Apakah anak menjadi deviant berasosiasi dengan strategi kontrol dari orangtua maupun guru? Eksplorasi jawaban, pertanyaan perilaku anak. Eksplorasi reaksi balik orangtua (perilaku, perkataan, perasaan, pikiran terhadap reaksl anak).

7. Adakah perbedaan pengajaran moral antar anak? Eksplorasi frustrasi dan perilaku sosjal yang diterapkan pada anak.

8. Sangsi apa yang iangsung diberikan oleh orangtua kepada anak jika anak melakukan pelanggaran? Jika tetap ngeyel (bahasa Jawa) apa yang dlilakukan orangtua.

Petunjuk wawancara dengan anak:

1. Nah, sekarang kita mau ngobrol sebentar. Apa pengaiaman di sekolah yang menyenangkan?

2. Kalau tidakmenyenangkan apa?

3. Apakah pernah melanggardisiplin (rumah dan alau sekolah)?

4. Apa yang dilakukan orangtuamu jika kamu melanggar disiplin?

5. Apakah kamu pernah berantem dengan kakak atau adikmu? Lalu bagaimana penyelesalannya?

Pendekatan anailsis yang digunakan daiam penelitian ini adalah model interaktif sebagaimana yang dikemukakan oleh Miles dan Huberman (1992) yaitu:

1. Pengumpulan data, data dikumpulkan darl dua macam sumber yaitu pengamatan dan wawancara naturalistik. Keduanya direkarn selain dengan cara mencatat saat pengamatan dilaksanakan juga direkam secara audio saat proses wawancara berlangsung.

2. Mereduksi data dengan membuat koding dan kategori berdasaikan pertanyaan penelitian.

3. Menyajikan data dalam bentuk teks naratif

4. Menylmpulkan dan membuat rekomendasi.

\section{Has ill}

Berikut, secara berturut-turut dlsampaikan hasil analisis data kualitatif disertal dengan kutipan-kutipan naratif dari dua sumber data, yaitu observasi dan wawancara berdasarkan pertanyaan penelltian yang telah dikemukakan:

1. Perilaku oposisi yang ditunjukkan siswa/anak sewaktu proses interaksi berlangsung: a) tidak mengerjakan tugas, b) ramai ketika pelajaran tengah berlangsung; c) makan sambil berjalanjalan; d) meminjam tanpa ijin; e) memegang kepala teman; f) mendominasi dalam permainan; g) anak mengaku tidak solat; h) ribut/"usrek", gerak terus selama mengikuti pelajaran; i) berkomentar ketika guru sedang menerangkan; i) mengucapkan kata-kata kotor; k) tidak mau disuruh; i) bertengkar dengan teman; m) tidak mengucapkan terima kasih.

2. Nilai rnoral yang dlajarkan di sekoiah dan di rurnah. Ketika diajukan pertanyaan kepada guru Taman Bermain dan Taman Kanak-kanak Ceria-Timoho mengenai nilal moral apa yang diajarkan di sekolah tersebut, disampalkan jawaban sebagai berikut: kepedulian dan empati; kerjasama, keberanlan, kemandirian, percaya dlri, rasa bangga, sikap menghormatl, tanggung jawab dan toleransi. Didukung dart hasil rekaman saat observasi berlangsung sebagai berikut:

" Miss Athony merebut mainanku"!!! " Athony aku keberatan!". Maaf Athony 
tidak merebut, minta ijin dulu. Kresna dah main duluan, maaf Athony, kembalikan say sorry to Kresna".

"Aku keberatan Ming !! - Miss, Aming bilangin aku bodoh"!!!. "Aming. Tatan keberatan dan itu kata-kata yang tidak baik diucapkan, say sory to Tatan,"

"Terimakasih Athony sudah mau berbagi" That's good".

Selanjutnya temuan agak berbeda, nilai moral yang diajarkan di Sokolah Dasar Taman Siswa, adalah sebagai berikut: kepedulian, empatl, slkap menghormati, tanggung Jawab dan toleransi. Berikut adalah kutipan-kutipan pernyataan guru sewaktu proses pembelajaran berlangsung.

"renggo, jangan ganggu temannya terus nanti saya suruh berdiri d depan kelas, Renggo !!!".

"Nullsnya kok kayak ginl, tho?" Emoh aku kalau nulisnya kayakglni"

"Tidak boleh nyontek!!!" kalau nyontek bod ho, tidak bisa pinter, tidak naikkelas !" "Kalau orek-orek jangan di buku matematikanya!!!".

"Ayo yang rapi, biasanya Renggo nggak rapi!!!"

- Empat bangku wis maju, sing apik bangku yang kompak!!"

- Siapa yang buang bungkus d sini ya ? (anak-anak diam) Ingat, nggak boleh buang sampah sembarangan seperti kata ibu kepala sekolah tadi "!?".

Taman Pendidikan Al'Quran menanamkan nilai kesopanan, menjadi anak muslim yang sholeh, dan tertib. Berikut kutipan yang diungkapkan baik oleh orangtua maupun Ustadz dalam rangka mengajarkan nilai kesopanan .

"Kowe mbok ora ngene"

"Berjanji demi Allah. "Kuberjanji nggak akan ramal lagi", gitu kalau ramai nantl sangsinya apa"

Sekolah Dasar Islam Terpadu menekankan pada pengajaran akhlak seperti mengucapkan terimakasih. memlnta maaf, mengucapkan salam, tidak berbohong, tidak meremehkan siapapun serta tanggung jawab. Adapun kutipan ungkapan guru terhadap siswa sewaktu diamati of kelas temyata tidak sejalan dengan hasil wawancara. Guru sering menegur siswa, guru mendominasi penuh kegiatan belajar sehingga siswa kurang memiliki inislatif. Siswa ditegur dengan kalimat negatif atau ancaman mlsalnya sebagai berikut:

"Awas kalau tidak bisa, yah"

"Kalau keluar dalam soal tidak boleh salah"

"Yang tidak baca berdiridi depan "

"Yang tidak menulls nantl tambah pelajaran sampal malam"

"Yang tidak menulis belajarnya sama ayam"

"'Besok kalau ada pelajaran Qiro'ah dan tauhid bukunya dibawa ya, kalau tldak dibawadilkat".

Sekolah Minggu menekankan pada nilai kekristenan dan kasih sayang, empati. Contoh ungkapan yang disampaikan oleh pemblmbing sekolah minggu sebagai berikut:

"Itu temannya nyanyi apa, temannya nyanyi"

"Ayo duduk yang man is, ya"

"tni domba kecil yang nakal, awas jatuh"

"Ayo duduk, kita mau pulan g. Nanti nggak pulang-pulang tho".

" Coba lihat ... Oh Anak Tuhan yang manis" (Guru berusaha meraih subjek)

"Eh nggak boleh nendhang, kalau nggak mau ditendang ya jangan nendang"

Hasil pengamatan d rumah tidak terlalu jauh berbeda nilai moral yang diajarkan, namun belum tampak nyata. Hal ini diduga kesempatan melakukan pengamatan terbatas, mengingat kedua orangtua subjek bekerja hingga malam. Dengan kata lain sulit mendapatkan kesempatan melakukan pengamatan saat orangtua dan anak berinteraksi. Hanya sesekali terllhat ibu mengulang pernyataan dengan nada keras dimaksudkan untuk mengingatkan anak agar mau belajar.

"Andi belajar sekarang" Hentikan nonton Tvnya" 
3. Media dan cara mengajarkan nilai moral. Terdapat persamaan media dan cara pembelajaran balk Sekolah Dasar Islam Terpadu maupun Taman Pendidikan A Quran yaitu mengacu pada kitab Al Qur'an serta kisah-kisah teladan Kehidupan Nabi.Adapun caranya dengan mendongeng kisah Nabi dan pengalaman hidup orang disekitar mereka tinggal, cerdas cermat, bermain sandiwara atau simulasi serta dongeng binatang, dengan cara mengulangngulang isi cerita agar pesan moral tersampaikan. Contoh kisah yang sering disampaikan adalah Kisah Nabi Adam diusir dari surga karena terbujuk oleh bisikan setan, maka ditanamkan setan adalah musuh orang Islam. Selain itu dongeng yang sering disampaikan kancil nyolong timun dimaksudkan agar anak tidak berbohong; cerita Gadjah sombong digigit semut yang bertujuan untuk menyampaikan nilai moral mengajarkan tidak sombong. Ungkapan-ungkapan yang sering disampaikan guru maupun Ustadz ketika menghadapi siswa yang ribut misalnya dengan mengajukan pertanyaan. "Hayo mau jadi anak shalih, tidak"?. "Kai as ramai seperti itu temannya setan". "Kalau kamu nakal terus namamu tak tulis of papan tulis". Tidakjarang guru menegur dengan cara mengancam seperti kutipan berikut ini " Yang nggak nulis nanti tambah pelajaran sampal malam". "Yang tidak menulis belajarnya sama ayam". "Besok kalau ada pelajaran Kiroah dan tauhid bukunya dibawa ya, kalau tidak diikat." "Yang tidak bisa nan ti habis ashar pelajaran lagi". "Kelompok yang ramai pasti gak bisa, banyak setannya." "Yang tidak diam, tidak istirahat, tidak makan". "Kalu jalan temantemannya setan, hii .. banyak setan".

Bahan Pengajaran Kebaktian Anak Gereja Kristen Jawa, digunakan sebagai acuan penyampalan nilai moral. Di dalam panduan tersebut telah termuat materi dan cara menyampaikan apakah dengan cara bermain, bernyanyi, merangkai kata, menyusun puzzle, serta memberi makna cerita dan mengaitkan dengan kehidupan sehari-hari atau dongeng dan diakhiri dengan pokokpokok perenungan, yang sebelum disampaikan tentunya dipelajari terlebih dahulu oleh para pengasuh yang akan bertugas.

Selanjutnya tidak ada kejelasan sumber acuan yang digunakan untuk mengajarkan nilai moral baik d SD Taman Siswa, Taman Bermain , Taman Kanak-kanak Ceria maupun di rumah. Dengan kata lain di setting tersebut digunakan beragam sumber, seperti misalnyafilm, dongeng maupun artikel.

4. Adakah ungkapan bahasa Jawa yang digunakan untuk menyampaikan nilai moral ? Tidak ada satupun guru, ustadz maupun orangtua yang menggunakan ungkapan bahasa Jawa dengan berbagai alasan seperti kutipan naratifberikutini:

" Saya jarang pakai bahasa Jawa jawa gitu, soalnya ya .. pakai basa ngoko gitu, nggak tau pake ukara-ukara, gitu."

Terkadang dalam menasehati menggunakan bahasa campuran bahasa Inggris, bahasa Jawa dan bahasa Indonesia, namun tidak mengutip proverb bahasa Jawa, contoh kutlpan naralif sebagai berikut:

"Balk nggak anak yang jujur?" ." Bisa diconto? Nek kowe gawene ngapusi ora apik!!!" (disampaikan sesudah memberi contoh tembang berjudul 'aku ora dora").

- Wah hebat lho, bisa mengerjakan tanpa dibantu"

"That's great honey..."

"Good boy/girl"

Tidak ada nllal-nilai kejawen yang diajarkan dengan ulasan ungkapan menggunakan bahasa Jawa ngoko, guru lebih memilih menggunakan ungkapan tentang anak muslim (sholeh).

"Tidak ada nilai-nilai kejawen yang diajarkan yang ada adalah nilai-nilal universal dengan alasan pluralisme jemaat".

"Tidak ada nilai-nalai Jawa yang tersirat, fokus pada nilai-nalai yang islami"

Ungkapan temannya setan sering disampaikan sebagai cara menurunkan harga diri anak. 


\section{Pembahasan}

Nilai moral yang diajarkan di sekolah dan di rumah memiliki perbedaan dalam penerapannya. Penanaman nilai moral di sekolah lebih bersif at social desirebility dan ada rasa "sungkan" dari guru ketika berhadapan dengan siswa di sekolah. Di lingkungan sekolah, guru akan mengajarkan nilai-nilai moral melalui tema-tema yang disampaikan sesuai mata pelajaran yang diajarkan dengan memberikan contoh kehidupan sehari-hari serta melalui cerita keteladanan. Nilai moral yang diajarkan lebih banyak berkaitan dengan penyelesaian tugas sekolah dengan baik dan cara berinteraksi dengan orang lain, baik itu teman, guru, maupun orang tua. Tenggang rasa, kejujuran, keberanian, memaafkan adalah nilai moral yang lebih banyak disampaikan oleh guru kepada siswa di sekolah. Dengan kata lain, belum semua nilai moral yang pokok disampaikan baik oleh guru, ustadz, pengasuh guru sekolah minggu, maupun orang tua. Nilai moral seperti kepedulian dan empati, kerjasama, keteguhan hati, komitmen, adil, suka menolong, humor, mandiri dan percaya diri, loyalitas, sabar, banyak akal, slkap menghargai serta toleransi (Schiller dan Bryant, 2002).

Hal ini diduga adanya perbedaan buku acuan dan fokus di masing-masing setting tempat pembelajaran siswa/anak. Pada setting Taman Pendidikan Al-Qur'an, dan Sekolah Dasar Islam Terpadu mengacu pada kitab suci AI-Qur'an menekankan nilai-nilai islami seperti menghafal Al Quran dan membaca Al Quran dengan baik (Mujidn, tt). Sedangkan pada sekolah Minggu menggunakan panduan Bahan Pengajaran Kebaktian Anak Gereja Kristen Jawa (Deputat PWG Sinode GKJ XXIII, 2004)yang merupakan pemaknaan ke dalam kehidupan sehari-hari, yang disusun secara sistematis. Adapun urutan penyajian materi sebagai berikut: pokok bahasan bersumber dari Al Kitab misalnya Lukas, Matius, Tujuan pembelajaran, pokok renungan bagi pengasuh, sinopsis cerita evaluasi berupa pertanyaan yang diajukan kepada anak untuk menjajagi sejauh mana pemahaman siswa akan isi materi. Aktivitas dapat berupa bemyanyi, menyusun puzzle, merangkai kata-kata atau bermain.

Sejauh pengamatan peneliti belum ada panduan yang baku baik di SD Taman Siswa, Taman Bermain dan Taman Kanakkanak Ceria. Dengan kata lain artinya ke tiga tempat tersebut menggunakan beragam sumber pembelajaran nilai moral. Sekolah Dasar Taman Siswa, belum memperkenalkan nilai-nilai ajaran K Hadjar Dewantara tentang kehidupan kepada siswanya, yang disampaikan merupakan riwayat dan perjuangan $\mathrm{KJ}$ Hadjar Dewantara pada masa penjajahan Belanda.

Namun demikian, tidak banyak guru, ustadz, pengasuh maupun orang tua yang menyampaikan nasehat atau teguran menggunakan ungkapan bahasa Jawa. Penyampaian nilai moral lebih banyak menggunakan bahasa Indonesia sebagai pengantar di sekolah dan disisipkan di selasela kegiatan belajar mengajar, terutama ketika ada siswa yang menunjukkan perilaku oposisi. Misalnya ketika ada siswa yang tidak bertanya karena takut salah, maka guru menegur dengan mengatakan "Malu bertanya sesat di jalan".

Berbeda halnya dengan penanaman nilai moral di rumah. Orangtua merasa lebih bebas untuk mengatur anaknya sehingga rasa sungkan tidak menjadi alasan kecuali ketika ada orang lain yang hadir dalam keluarga tersebut. Orangtua akan langsung menegur anaknya ketika melakukan sesuatu yang dianggap salah atau justru membiarkan saja. Teguran yang disampaikan oleh orang tua lebih banyak bersifat 'memarahi' dan bukan menasehati. Kata-kata berupa larangan juga digunakan untuk menegur perilaku anak, misalnya pada kasus di atas ketika anak mencoba mengungkapkan pendapatnya mengapa hadiah untuk kakaknya lebih bagus, kemudian orangtua mengatakan, "E ...tidak boleh begitu". Pengajaran nilai morai di rumah disampaikan ketika muncul perilaku oposisi anak yang dinilai negatif oleh orang tua maupun lingkungan sosialnya. Masih jarang orangtua 
yang menanamkan nilai moral ketika anak berperilaku positif atau disampaikan di selasela anak bersama dengan orang tuanya. Nilai moral yang diajarkan of rumah lebih banyak berkaitan dengan kepatuhan terhadap orangtua, disiplin, dan rajin.

Temuan yang menarik dalam penelitian ini adalah pengajaran nilai moral oleh orangtua di sekolah, yaitu ketika orang tua berperan sebagai guru. Lebih banyak orang tua yang membiarkan saja ketika anaknya berperilaku negatif saat orangtua, dalam hal Ini ibu, sedang menyampaikan materi pelajaran. Seperti yang terjadi di sekolah minggu, anakcenderung berperilaku oposisi dan ibu membiarkan saja seolah-olah keberadaan anak tidak ada disitu. Pengajaran nilai moral tidak banyak disampaikan, namun guru tetap mencoba menyampaikan melalui kisah keteladanan dan contoh sehari-hari. Nilai moral yang diajarkan dikaitkan dengan tema yang disampaikan sesuai dengan materi ajarnya. Penyampaian melalui kata-kata untuk menegur perilaku anak masih bersifat larangan, seperti yang disampaikan oleh guru. "Eh, nggak boleh nendhang, kalau nggak mau ditendang ya jangan nendhang. Anak Tuhan nggak boleh nendhang".

Dari ketiga temuan di atas, dapat dilihat kesamaan dalam pengajaran nilai moral, yaitu lebih banyak disampaikan melalui kata-kata teguran dan berupa larangan terutama ketika muncul perilaku oposisi. Larangan-larangan yang diutarakan tidak disertai alasan-alasan kenapa tidak boleh dilakukan sehingga anak cenderung untuk tidak merespon dengan baik teguran yang disampaikan karena perilaku oposislnya tersebut. Sedangkan perilaku positif kurang ditanggapi oleh orangtua maupun guru dan diberi reward supaya perilaku positif tersebut menguat sehingga pengajaran nilal moral akan lebih efektif.

Berdasarkan temuan di tujuh setting ternyata pembelajaran moral belum mempertimbangkan tahap perkembangan kognitif anak yaitu pada tahap preoperasional dengan ciri berpikir berdasarkan pada perasaan bukan logika. Mereka memiliki Imajinasi yang baik tentang sesuatu, namun menemui kesulitan untuk melihat dari perspektif yang lain (Www.wcg.org.lit/ disc/moraledu.html). Ajaran kasih sayang, mencintai dan saling memaafkan merupakan moral dasar yang merupakan moral utama yang harus disampaikan pertama kali, belum nampak diajarkan di tujuh setting.

Pelajaran moral yang dimaksudkan untuk mengajar kepatuhan adalah kebenaran sesuai dengan teori tahap perkembangan moral dari Kohlberg (www.wcg.org. lit/disc/mo ra led u. html). Namun kepatuhan diajarkan dengan cara memberi ancaman, artinya belum digunakan pendekatan persistent persuasion. Perilaku negatif akan muncul jika penanaman moral tanpa memberi reward (Stormzhak dan Stratton, 1999). Sementara hasil penelitian menunjukkan anak akan termotivas I untuk menglkuti aturan jika diberi reward darlpada jika diberi punishment (www.wcg.orgllt disc/moraledu.html). Namun demikian, peneliti percaya bahwa manusia selalu mempunyal potensi untuk berkembang tumbuh ke arah kematangandiri.

Kenyataan menunjukkan bahwa orangtua tldak terlalu berperan dalam penanaman moral pada subjek penelitian ini, sementara bukti penelitian menunjukkan bahwa moralitas tergantung pada apa yang diajarkan orangtua kepada anak (www.wcg.org.lit/disc/moraledu.html), karena penanaman nilai moral bukanlah sesuatu yang otomatis. Belum sepenuhnya persistent persuasion berhasil dilakukan karena cara penyampalan nilai moral dengan cara-cara mengancam dan disertai dengan perubahan nada suara (Bergin dan Bergin, 1999).

\section{Penutup}

Sebagai penutup dapatlah disampaikan di sini butir-butir temuan penelitian yang perlu dicermati bersama sebagai bahan untuk kajian lebih lanjut mengenai topikyang serupa:

1. Nilai moral yang dlajarkan di sekolah adalah tegang rasa, kejujuran, keberanian, disiplin, dan memaafkan. Sedangkan nilai moral yang diajarkan of 
rumah lebih ditekankan pada kepatuhan terhadap orangtua, disiplin, dan raj in.

2. Cara mengajarkan nilai-nilai moral tersebut memiliki kesamaan dan perbedaan antara di sekolah dengan di rumah. Kesamaan pengajaran nilai moral baik di sekolah maupun di rumah adalah nilai-nilai moral yang disampaikan melaiui kata-kata baik itu berupa teguran maupun larangan ketika muncul perilaku oposisi. Sedangkan perbedaannya adalah di sekolah pengajaran nilaí moral disampaikan ketika pelajaran berlangsung sesuai dengan tema atau materl ajarnya dan di rumah pengajaran nilai moral leblh leluasa untuk disampaikan kapanpun dan dalam bentuk apapun tidak terbatas oleh waktu.

3. Media yang digunakan untuk mengajarkan nillai-nilal moral di sekolah lebih banyak menggunakan cerita atau kisah keteladanan dan contoh seharl-hari. Sedangkan di rumah, materi untuk mengajarkan nilai-nilal moral masih belum nampak karena orang tua lebih banyak menggunakan kata-kata langsung untuk menegur, melarang serta menasehati.

Ungkapan bahasa Jawa tidak digunakan untuk mengajarkan nilai-nilai moral pada anak balk itu di rumah maupun di sekolah. Namun ada ungkapan dalam bahasa Indonesia yang digunakan untuk menyampaikan nilai-nilai moral yang diajarkan oleh guru di sekolah

\section{Kepustakaan}

Andayani, B. 2000. Profile Keluarga Bermasalah. Jurnal Psikologi. Desember.

Bergin, C. dan Bergin, D. 1999. Classroom Discipline That Promotes Selfcontrol. Journal of Applied Developmental Psychology. 20 (2): 180-206

Darusuprapto, dkk. 1985. Ajaran Moral dalam Sastra Suluk. Fakultas Sastra. Yogyakarta: Universitas
Gadjah Mada

Fagot, B.I. 1995. Classification of Problem Behaviors in Young Children: A Comparison of Four Systems. Joumal of Applied Developmental Psychology 16. p 95-106.

Gardiner, W.H. dan Kosmitzki, C. 2002. Lives Across Cultures. Boston: Allyn and Bacon

Gottman, J.\& Mettetal, G. 1987. Speculations about social and affective development: Friendship and acquaintship through adolescence. in J.M. Gottman \& J. Parker (Eds). The Consersations of friends : Speculations on affective development (pp 192-240). New York: Cambridge University Press.

Imhoff, M.C. Dam BakerWard, L 1999. Preschoolers Suggestibility: Effects of Delopmentally Appropriate Language and Interview Supportiveness. Joumal of Applied Developmental Psychology. 20 (3): 407 - 429

Ladd, G.W.\& Price,J.P. 1987. Predicting children's social and school adjustment following the transition from preschool b kindergarten. Child Development, 58. 16-25.

Lakso, M. 1999. Mother's and Father's Communication Clarity and Teaching Strategies With Their School- Aged Children. Joumal of Applied Developmental Psychology, 16: 445-461.

Luria, A.R. 1971. Human Brain and Psychological Process. Moscow: Pedagogica Publication.

Marcia, J.E. 1999. Representational thought in ego identity, psychoterapy, and psychosocial developmental theory. in I.E. Sigel.(Ed). Development of mental 
representation: Theories of applications. Mahwah, NJ. Erlbaum.

Miles dan Huberman, 1992. Analisis Data Kualitatif: Buku Sumber tentang Mefode- metode Baru. Ter jemahan: Rohidi. Jakarta: Penerbit Universitas Indonesia.

Saywitz, K 1995. The Question, the answer, and the environment. In $\mathrm{M}$. Zaragoza, J.R.

Graham, G. C.N. Hall, \& Y.S. Ben-Porath (Eds), Memory and Testimonyin the child witness (pp 113-140). Thousand Oaks, CA: Sage Publications.

Shantz, C.U. \& Hobart,C.J. 1989. Social Conflict and Development: Peers and siblings. In T.J. Berndt \& G.W. Ladd (Eds), Peer relationships in child development ( $p$ p 71-94). New York: Wiley.
Shiraev, E. dan Levy, D. 2004. Cross-Cultural Psychology Critical Thinking and Confemporary Applications. New York Pearson

Stormshak, E.A dan Webster Stratton, C 1999. The Qualitative Interactions of Children With Conduct Problems and their Peers: Differential Correlates with Self

Report Measures, Home Behavior, and School Behavior Problems. Journal of Applied Developmental Psychology 20 (2): 295-317.

Vuchinich, S, Vuchinich, R, \& Coughlin, C. (1992). Family talk and par ent-child relationships: Toward integrating deductive and inductive paradigma. Merrill Pulmer Quarteriy, 38, 69-93. 